\title{
CMR ventriculometry for evaluation of ecg hypertrophy criteria in a preventive medicine population
}

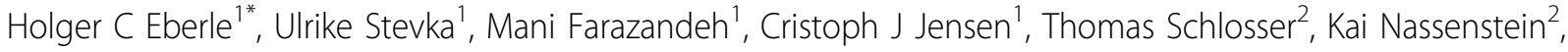 \\ Christoph K Naber', Georg V Sabin', Oliver Bruder ${ }^{1}$
}

From 2011 SCMR/Euro CMR Joint Scientific Sessions

Nice, France. 3-6 February 2011

\section{Introduction}

Left ventricular hypertrophy (LVH) is an important prognosticator for cardiovascular $(\mathrm{CV})$ risk in persons with and without arterial hypertension. Given the high prevalence of these conditions, LVH screening is mandatory for $\mathrm{CV}$ prevention. Although not evaluated in a middle aged preventive medicine population, Electrocardiography (ECG) is widely used for LVH screening. Although not widely accessible as a screening technique, cardiovascular magnetic resonance (CMR) offers a unique opportunity to calculate LV mass index (LVMI) as the gold standard for other diagnostic tests.

\section{Purpose}

To assess the reliability of ECG LVH criteria compared to CMR ventriculometry (cutoff: LVMI $83 \mathrm{~g} / \mathrm{m}^{2}$ ) and the incremental value of CMR in a population from a prevention programme.

\section{Methods}

220 (206 male, age $49.5 \pm 8,4$ years) consecutive participants of a prevention programme without known heart disease underwent CMR in a $1.5 \mathrm{~T}$ scanner (Magnetom Avanto, Siemens, Erlangen, Germany) including SSFP Cine (TrueFISP TR 3ms, TE $1.5 \mathrm{~ms}$, FA $72^{\circ}$, slice thickness $6 \mathrm{~mm}$ ) and delayed enhancement imaging.

LVMI was derived from contiguous short axis cine images using the summation of discs method. These data were compared to Sokolow-Lyon amplitude, Sokolow-Lyon duration product, Cornell amplitude, Cornell

'Elisabeth Hospital Essen, Essen, Germany

Full list of author information is available at the end of the article duration product, and Romhild-Estes score (Tables 1,2) in 12 lead ECG.

\section{Results}

31 participants had positive LVH criteria in ECG, of which 6, and 4 ECG negatives, showed LVH (LVMI > $83 \mathrm{~g} / \mathrm{m}^{2}$ ) in CMR (Figure 2). All ECG criteria were positively correlated with LV mass (Table 3 ). Specificities and negative predictive values were high in our low-

Table 1 Calculation of the ECG criteria

\begin{tabular}{|c|c|c|}
\hline Criterion & Calculation & $\begin{array}{l}\text { Normal } \\
\text { value }\end{array}$ \\
\hline Sokolow-Lyon Amplitude (mV) & SV1 + RV5/N6 & $<3,5$ \\
\hline $\begin{array}{l}\text { Sokolow-Lyon Duration Product } \\
\left(\mathrm{mm}{ }^{*} \mathrm{~ms}\right)\end{array}$ & $\begin{array}{l}(\mathrm{SV} 1+\mathrm{RV} 5 / \mathrm{N} 6) * \mathrm{QRS} \\
\text { duration }\end{array}$ & $<2940$ \\
\hline Cornell Amplitude (mV) & $\mathrm{R} a \mathrm{VL}+\mathrm{SV} 3$ & $<2,8$ \\
\hline $\begin{array}{l}\text { Cornell Duration Product } \\
(\mathrm{mm}+\mathrm{ms})\end{array}$ & $\begin{array}{l}(\mathrm{R} \text { aVI }+\mathrm{SV} 3) * \mathrm{QRS} \\
\text { duration }\end{array}$ & $<2440$ \\
\hline
\end{tabular}

\section{Table 2 Romhild Estes Score}

\begin{tabular}{ll}
\hline Criterion & Points \\
\hline $\mathrm{R}$ or $\mathrm{S}>20 \mathrm{~mm}$ & 3 \\
or & \\
$\mathrm{S}$ in $\mathrm{V} 1$ or $\mathrm{V} 2>30 \mathrm{~mm}$ & \\
or & \\
$\mathrm{R}$ in $\mathrm{V} 5$ or $\mathrm{V} 630 \mathrm{~mm}$ & 1 \\
$\mathrm{ST} / \mathrm{T}$ changes typical of $\mathrm{LVH}$, taking digitalis & 3 \\
$\mathrm{ST} / \mathrm{T}$ changes typical of $\mathrm{LVH}$, not taking digitalis & 3 \\
$\mathrm{P}$ terminal force in $\mathrm{V} 11 \mathrm{~mm}$ or more, duration $>40 \mathrm{~ms}$ & 2 \\
Left axis deviation $>-30^{\circ}$ & 1 \\
QRS dura $90 \mathrm{~ms}$ & 1 \\
Intrinsicoid deflection in $\mathrm{V} 5$ or $\mathrm{V} 6>50 \mathrm{~ms}$ &
\end{tabular}




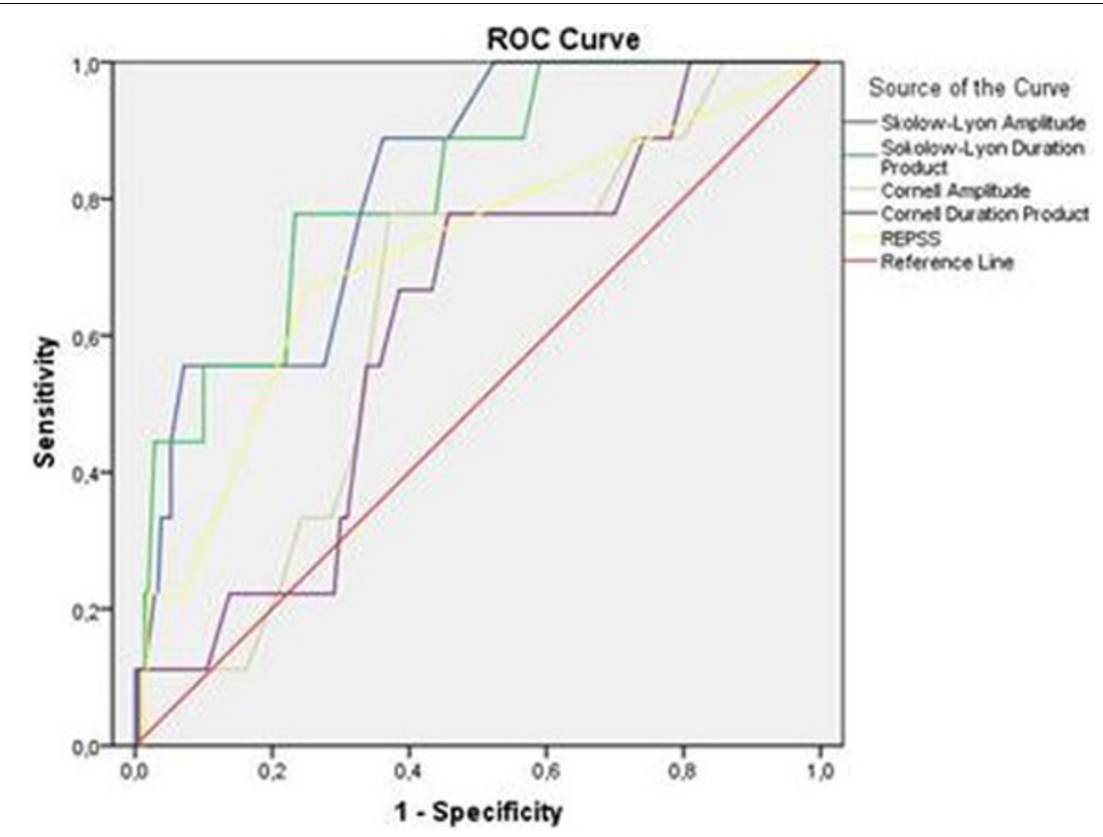

Figure 1 ROC analysis of the ECG criteria to identify LVH

Table 3 Diagnostic characteristics and correlation with LVMI of the ECG criteria

\begin{tabular}{|c|c|c|c|c|c|}
\hline Criterion & Correlation Coefficient (Perason) & Sensitivity & Specificity & Posisitive Predictive Value & Negative Predictive Value \\
\hline Sokolow-Lyon Amplitude & 0.413 & 0.52 & 0.94 & 0.26 & 0.98 \\
\hline Sokolow-Lyon Product & 0.436 & 0.44 & 0.92 & 0.18 & 0.92 \\
\hline Cornell Amplitude & 0.224 & 0.111 & 0.97 & 0.14 & 0.95 \\
\hline Cornell Product & 0.231 & 0.2 & 0.97 & 0.11 & 0.96 \\
\hline REPSS & 0.248 & 0.22 & 0.93 & 0.12 & 0.97 \\
\hline
\end{tabular}

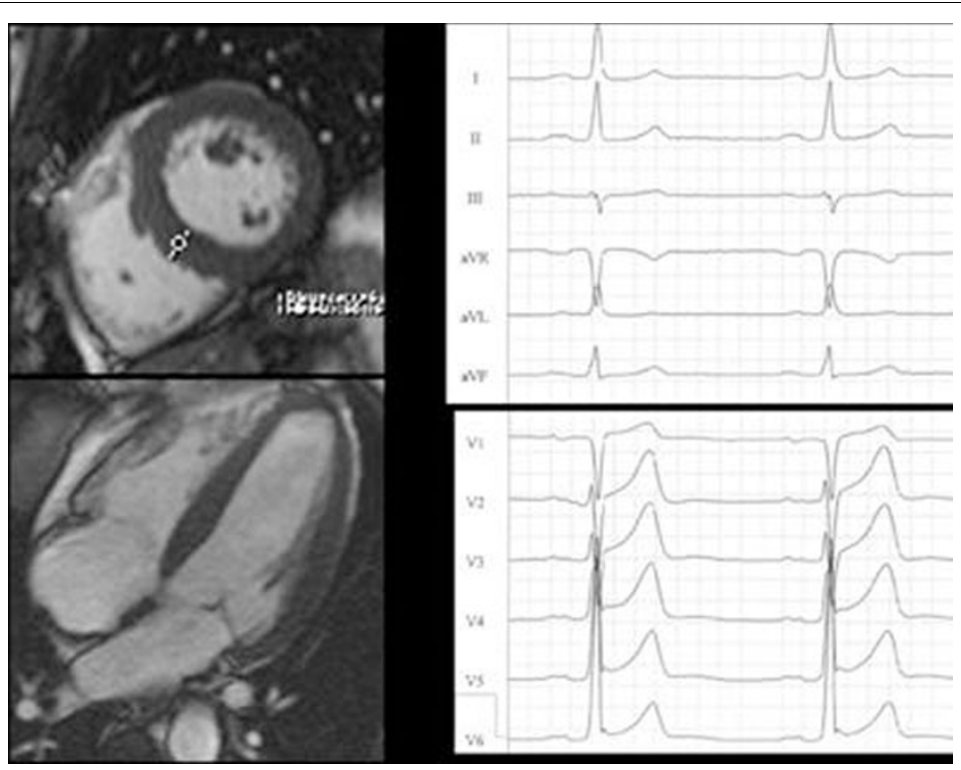

Figure 2 CMR showing LVH with increased LVMI and septal thickness, in a patient with pathologic Sokolow-Lyon Index, Sokolow Duration Product, and REPSS. 
prevalence population, but sensitivities and positive predictive values were poor (Table 3, Figure 1).

\section{Conclusions}

CMR identified a large proportion of false positive ECG results (25/31), and identified additional $\mathrm{LVH}$ cases (4/189). ECG is not a reliable LVH screening tool in a middle aged prevention population. LVH screening should be based on imaging techniques.

\section{Author details}

${ }^{1}$ Elisabeth Hospital Essen, Essen, Germany. ${ }^{2}$ University Hospital Essen, Essen, Germany.

Published: 2 February 2011

doi:10.1186/1532-429X-13-S1-P244

Cite this article as: Eberle et al:: CMR ventriculometry for evaluation of ecg hypertrophy criteria in a preventive medicine population. Journal of Cardiovascular Magnetic Resonance 2011 13(Suppl 1):P244.

Submit your next manuscript to BioMed Central and take full advantage of:

- Convenient online submission

- Thorough peer review

- No space constraints or color figure charges

- Immediate publication on acceptance

- Inclusion in PubMed, CAS, Scopus and Google Scholar

- Research which is freely available for redistribution

Submit your manuscript at www.biomedcentral.com/submit
() Biomed Central 